\title{
Effect of Superheated Steam Roasting on Radical Scavenging Activity and Phenolic Content of Robusta Coffee Beans
}

\author{
Ooi Ee Shan", Wahidu Zzaman",*, Tajul A. Yang ${ }^{\#, 1}$ \\ \# Food Technology Division, School of Industrial Technology, Universiti Sains Malaysia, 11800 Pulau Pinang, Malaysia. \\ E-mail: ${ }^{1}$ taris@usm.my \\ *Food Engineering and Tea Technology, Shahjalal University of Science and Technology, Sylhet-3114, Bangladesh. \\ E-mail: wahidanft@yahoo.com
}

\begin{abstract}
Robusta coffee is one of the coffee species grown in Malaysia. However, there is little research conducted on Robusta coffee beans as Arabica coffee is more popular among the consumers. Coffee is a rich source of antioxidants, therefore research on antioxidant properties of Robusta coffee beans is important to explore its market value. Nowadays, most of coffee analysis is on conventional roasted coffee which reduces their antioxidant properties. In this study, Robusta coffee beans (Coffea canephora) were subjected to superheated steam roasting at 200,220 and $240{ }^{\circ} \mathrm{C}$ for $20-40$ min to obtain light, medium and dark roast. The effect of different roasting temperature and time on the total phenolic content (TPC) and radical scavenging activity (RSA) of Robusta coffee bean was investigated. Total phenolic content of coffee brews decreased with the increase of roasting degree due to the degradation of phenolic compounds. The highest phenolic content was found at $220{ }^{\circ} \mathrm{C}$ for $20 \mathrm{~min}$. Meanwhile, brews extracted from light roasted coffee and medium roasted at $220^{\circ} \mathrm{C}$ for 20 min showed a maximum scavenging activity than those from green coffee. Brews from dark roasted coffee showed lowest radical scavenging activity and total phenol content. Hence, based on the results from this study, the best superheated steam roasting condition is at $220{ }^{\circ} \mathrm{C}$ for $20 \mathrm{~min}$ (medium roast) to achieve a maximum antioxidant activity and highest phenolic content.
\end{abstract}

Keywords — Superheated steam roasting; Total phenolic content; Radical scavenging activity; Robusta coffee

\section{INTRODUCTION}

Demand for better quality coffee beverage is growing rapidly. Recently, different coffee origins are being sourced and new preparation methods are being devised. Coffee, prepared from the roasted coffee beans, is one of the most widely consumed beverages in the world for their physiological effects and attractive aroma and taste [34]. The green beans are, in fact, characterized by a flavourless, green-earthy aroma and exhibiting exceptional hardness due to the thick cell walls and lack of intracellular spaces, which impede them to be used as food. All the chemical, physical, structural and sensorial properties of green beans are changed remarkably by the intense thermal treatment of roasting, which include thermal degradation of natural phenolic antioxidants and generation of the flavour compounds [2]. Hence, the pleasant flavour of coffee originates from the roasting process, where the sensation of bitter quality and volatile aroma compounds are formed [37].

In recent years, there has been much interest in the healthenhancing roles of specific foods or physiologically functional foods [17]. Great attention has been paid to those foods that have the potential to exert its antioxidant activity. Antioxidants are substances which inhibit or delay oxidation of a substrate although present in minute amounts [13]. It can quench reactive oxygen species (ROS), such as free radicals, prevent the oxidation of other molecules and therefore, have health promoting effects in the diseases prevention [27], [14]. Scientific studies showed that moderate coffee consumption has health-promoting effect. Coffee contains rich source of compounds possessing antioxidant and radical scavenging activities [10], [32].

Coffee stands out for its antioxidant potential compared to other beverages and this may be due to its high content of polyphenols that contributes to its strong antioxidant activity [10]. Green coffee beans contain several polyphenolic antioxidants, such as chlorogenic acid, caffeic acid, ferulic acid and n-coumarinic acid [8]. The concentration of highly active polyphenols in green bean is influenced by the species and its origin [10], whereas in coffee beverages it is mostly dependent on the roasting conditions, much more than the brewing methods and source of coffee beans [36], [16]. The major antioxidant compounds in coffee is the polyphenol chlorogenic acid. Chlorogenic acids mainly include 
caffeoylquinic acids (CQA), dicaffeoylquinic acids (diCQA), and feruloylquinic acids (FQA) [19]. They are phenolic compounds formed by esterification of hydroxycinnamic acids, such as caffeic acid, ferulic acid and p-coumaric acid with quinic acid [23], [4]. Chlorogenic acids give astringency, bitterness and final acidity to the coffee brew. Chlorogenic acids are responsible for the bitterness of coffee due to release of caffeic acid as well as formation of lactones and phenolic derivatives during roasting [3]. Furthermore, it gives the roasted coffee flavor which determines the final coffee brew quality [5].

The impact of roasting on antioxidant activity of coffee brew has been studied by many researchers but the results are largely inconsistent. Some studies reported that higher roasting degree will increase the antioxidant activity of the coffee brew while others found that there is a progressive reduction in antioxidant activity at higher roasting degree. For example, [17] reported that during intense heat treatment of coffee, the antioxidant activity was found to be reduced by the formation of Maillard reaction products (MRPs). The overall antioxidant capacity of roasted coffee may be enhanced or maintained as the development of Maillard reaction during roasting seems to play a counter balancing role in the thermal degradation of naturally occurring phenolic compounds. In contrast, [10] reported that antioxidant activity increased up to the medium roasting degree but decreased at higher (dark) roasting degree.

Thus, the antioxidant activity of coffee brew is greatly influenced by the roasting process. In this study, the superheated steam roasting process will be introduced and its roasting condition on antioxidant activity of green and roasted coffee will be evaluated. During roasting, coffee beans are roasted at $200-240{ }^{\circ} \mathrm{C}$ depending on the degree of roasting (light, medium and dark roasted coffee). No experimental research has been performed in this area.

\section{MATERIAL AND METHODS}

\section{A. Sample Collection}

Robusta (Coffea canephora) green coffee beans were obtained from local Hang Tuah Coffee factory, Tasek Gelugor Seberang Prai, Malaysia. The beans were then subjected to selection processes manually at the laboratory of the Food Technology in the School of Industrial Technology of Universiti Sains Malaysia (USM). The defective beans (black, partly black, broken, infested) were discarded.

\section{B. Roasting}

A superheated steam oven (Healsio, AV-1500V, SHARP, Japan) with the superheated steam roast mode was used to roast all the coffee samples. The oven was preheated to the roasting temperature before roast. Bean $(100 \mathrm{~g})$ was roasted separately at the roasting temperature of 200 (light), 220 (medium), $240{ }^{\circ} \mathrm{C}$ (dark) for 20 to 40 minutes. The roasted beans were each ground into fine powder using a laboratory grinder and fractions of each were stored in the air-tight container for subsequent analyses.

\section{Preparation of Coffee Brews}

Ground coffee was prepared by solid-liquid extraction with distilled water. The ground coffee $(1 \mathrm{~g})$ was mixed with
$50 \mathrm{ml}$ of boiling distilled water and extracted for 15 minutes. After being cooled down to room temperature, the coffee brew was then centrifuged at $3500 \mathrm{rpm}$ for 5 minutes. The supernatant layer was used for analysis. All analyses were performed with freshly prepared coffee brews.

\section{Determination of Total Phenolic Content}

A spectrophotometric method [33] with slightly modifications was adopted for the determination of total polyphenols in the prepared coffee brews. Folin-ciocalteu reagent was used and a standard calibration curve was prepared using different concentrations of Gallic acid (0.5 $\left.0.1 \mathrm{mg} \cdot \mathrm{ml}^{-1}\right)$. A volume of $1 \mathrm{ml}$ of coffee brews was mixed with $10 \mathrm{ml}$ of $10 \%$ Folin-Ciocalteu (FC) reagent and $10 \mathrm{ml}$ of $7 \%$ sodium carbonate $\left(\mathrm{Na}_{2} \mathrm{CO}_{3}\right)$ solution. Then, $4 \mathrm{ml}$ of distilled water was added up to a final volume of $25 \mathrm{ml}$. Solutions were maintained in dark, at room temperature for 90 minutes and total polyphenol content was determined at $750 \mathrm{~nm}$ using UV-Vis 1240 Shimadzu spectrophotometer. The total phenolic content was calculated as Gallic acid equivalent (GAE) by the following equation: $\mathrm{T}=\mathrm{C} \times \mathrm{V} / \mathrm{M}$. $\mathrm{T}$ is the total phenolic content in $\mathrm{mg} \cdot \mathrm{g}^{-1}$ of the coffee brew as GAE, $\mathrm{C}$ is the concentration of Gallic acid established from the calibration curve in $\mathrm{mg}^{-\mathrm{g}^{-1}}, \mathrm{~V}$ is the volume of the extract solution in $\mathrm{ml}$ and $\mathrm{M}$ is the weight of the extract in $\mathrm{g}$ [38].

\section{E. Determination of Antioxidant Activity by DPPH- Scavenging Assay}

The free radical scavenging activity of the coffee brew was investigated using 1, 1-diphenyl-2-picrylhydrazyl (DPPH) radical scavenging according to the method of [15] with slight modification. Briefly, the sample contained 0.1 $\mathrm{ml}$ of coffee brew and $3.9 \mathrm{ml}$ of DPPH solution ( $5 \mathrm{mg}$ per $100 \mathrm{ml}$ of methanol). $A_{517}$ was measured immediately after the mixture was prepared. The control sample contained 3.9 $\mathrm{ml}$ of DPPH solution and $0.1 \mathrm{ml}$ of water. The activity in DPPH scavenging was expressed as a percentage and calculated from the following equation:

$$
\% \text { Inhibition }=\frac{A_{\text {control }}-A_{\text {sample }}}{A_{\text {control }}} \times 100
$$

\section{F. Statistical Analysis}

All measurements and analyses were carried out in triplicate. The results were analyzed statistically using two way analysis of variance method (ANOVA) to determine the effect of temperature and time on these responses. The ANOVA tests were performed using SPSS 13.0 (SPSS Inc., Chicago, IL, USA).

\section{RESULTS AND DISCUSSION}

\section{A. Total Phenolic Content}

Coffee is a beverage that is rich in antioxidant compounds which are usually in the phenolic form [20], [11]. Phenolic compounds are the main class of natural antioxidants present in plants and make a significant contribution to the total water-soluble antioxidant activity [11], [7]. The phenolic content of Robusta coffee beans were extracted with hot water in order to determine the amount of polyphenol 
content present in coffee brew as prepared by consumers. Folin-Ciocalteu method was used to assess the amount of phenolic compounds present in Robusta coffee and results were expressed as Gallic acid equivalents.

In general, a decreased in phenolic content was observed when the roasting temperature-time increased is shown in Figure 1. These results are in accordance with the study conducted by [22], which have shown that the total phenolic content of coffee brews decreased with the increase of roasting degree, at all temperature. Changes in the antioxidative capacity of coffee are related to the chlorogenic acids (CGAs) that present in green coffee bean. CGAs are the major source of antioxidant capacity in green coffee beans [30], [6]. Roasted beans contain less phenolic content than green beans as chlorogenic acid present in the green coffee was degraded upon roasting [24].

Green coffee has $18.75 \mathrm{mg}$ GAE/g of phenolic content. Meanwhile, at the first $20 \mathrm{~min}$ of roasting, light- and medium roasted coffee gave the highest phenolic content compared to the green coffee, $18.8 \mathrm{mg} \mathrm{GAE} / \mathrm{g}$ and $19.3 \mathrm{mg}$ GAE/g respectively. According to [21], chlorogenic acid content increased during the beginning stage of roasting due to the decomposition of phenolic acids. Heat treatment caused the cell wall disruption and thus soluble polyphenolic compounds released from insoluble ester bonds, leading to an increase in antioxidant capacity in the beginning stage of the roasting [1], [18], [35]. Besides, [25] also reported that formation of melanoidins and other Maillard reaction products during the early phases of coffee roasting may attributed to the higher antioxidant capacity at the first 20 min of light- and medium roasted coffee.

Polyphenolic contents decrease with an increase in the degree of roasting, hence dark roast coffee has the lowest phenolic content. Polyphenolic compounds are highly thermolabile compounds. Degradation of polyphenols caused by the oxidative condensation and decomposition of thermolabile compounds induced during the prolonged heat treatment [28], [31], [12].

However, our study has demonstrated that at 20 min of medium-roasted coffee $\left(220^{\circ} \mathrm{C}\right)$ gave the highest phenolic content compared to the other roasting condition. It is believed that upon application of a sufficient amount of heat, polyphenolic compounds in coffee are produced [9].

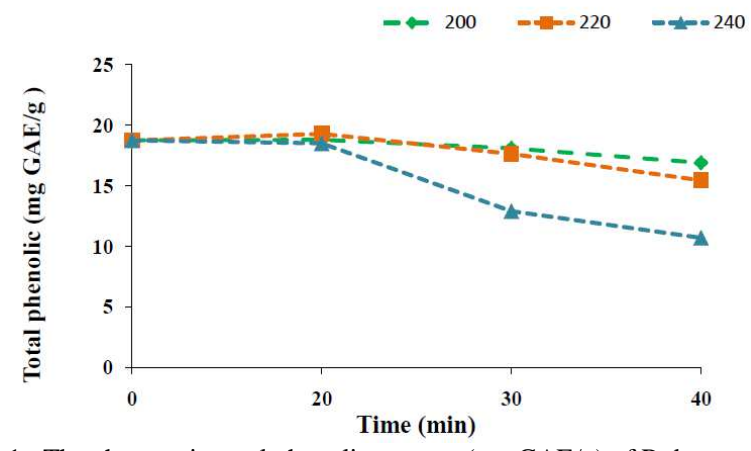

Fig. 1 The changes in total phenolic content (mg GAE/g) of Robusta coffee during superheated steam roasting

\section{B. Radical Scavenging Activity}

The free radical scavenging activities of the coffee beans were determined by the DPPH assay. It is widely used to investigate the antioxidant potential of a sample. DPPH is a stable, nitrogen centered free radical with a maximum absorption at $517 \mathrm{~nm}$. As the antioxidants donate protons to this radical, the absorption decreases. The principle behind this assay is that the antioxidants react with the stable free radical i.e. $\alpha, \alpha$-diphenyl- $\beta$-picrylhydrazyl (deep violet colour) and convert to $\alpha, \alpha$-diphenyl- $\beta$-picrylhydrazine with discoloration. The degree of discoloration indicates the scavenging potential of the sample [29]. The free radical scavenging activity of coffee brew was evaluated using DPPH method, and the results are shown in Figure 2.

The scavenging activity of superheated steam roasted coffee brew was in the order of light roasted > unroasted > medium roasted $>$ dark roasted. Our study was in accordance with the result from [11]. However, the scavenging activity at the first $20 \mathrm{~min}$ of medium roasted $(91.78 \%)$ in our study was observed to be higher than the unroasted coffee $(91.28 \%)$. It was reported by [26] that polyphenols are the major compounds that responsible for the free radical scavenging activity of coffee brew under mild roasting conditions, while Maillard reaction products (MRPs) are mainly responsible for the scavenging activity of medium and dark roasted coffee.

According to [16], medium roasted coffee brews have higher radical scavenging activity than unroasted coffee due to an increase of the radical scavenging activity of the nonphenolic fraction (NPF) upon roasting. On the other hand, dark roasted coffee exhibited lower radical scavenging activity due to the degradation of polyphenol during roasting process. Radical scavenging activity (RSA) of the nonphenolic fraction (NPF) increased gradually with the roasting intensity, while the RSA of the phenolic fraction (PF) decreased due to the thermal degradation of phenolic compounds [25].

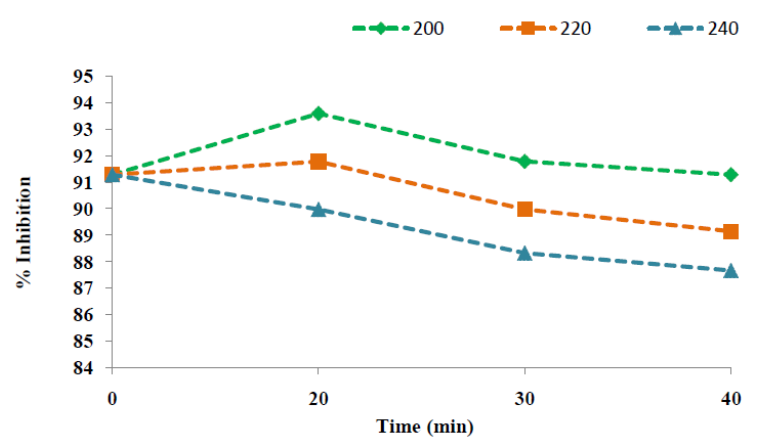

Fig. 2 Free radical scavenging activity of the Robusta coffee roasted using superheated steam at $200-240{ }^{\circ} \mathrm{C}$ for different time.

\section{CONCLUSIONS}

The results indicated that roasting degree (light, medium and dark) significantly influenced the total phenolic content and radical scavenging activity of the coffee beans. Total phenolic content of the coffee brew decreased as the roasting temperature and time increased. However, it is interesting to note that phenolic content at $220{ }^{\circ} \mathrm{C}$ for 20 min (mediumroast) is higher than unroasted (green) bean, light- and darkroasted coffee. This is very likely due to the production of polyphenolic compounds in coffee upon application of a sufficient amount of heat. DPPH assay has been widely used to determine the free radical scavenging activity due to its ease and convenience. Light- (200 ${ }^{\circ} \mathrm{C}$ for $\left.20-40 \mathrm{~min}\right)$ and 
medium-roasted $\left(220{ }^{\circ} \mathrm{C}\right.$ for $\left.20 \mathrm{~min}\right)$ gave higher radical scavenging activity than unroasted (green) bean and darkroasted coffee. Based on the results generated in this study, the authors conclude that superheated steam roasting can actually increase the antioxidant properties of coffee beans. Result showed that maximum antioxidant activity and phenolic compounds can be achieved at $220{ }^{\circ} \mathrm{C}$ for $20 \mathrm{~min}$ (medium roast) which is higher than the unroasted (green) bean.

\section{ACKNOWLEDGMENT}

We would like to acknowledge to the Fellowship Scheme of the Institute of Postgraduate Studies, Universiti Sains Malaysia for funding this research.

\section{REFERENCES}

[1] A. Chumyam, K. Whangchai, J. Jungklang, B. Faiyue, and K. Saengnil, "Effects of heat treatments on antioxidant capacity and TPC of eggplants," ScienceAsia, vol. 39, pp. 246-251, Mar. 2013.

[2] A. Fabbri, C. Cevoli, L. Alessandrini, and S. Romani, "Numerical modelling of heat and mass transfer during coffee roasting process," Journal of Food Engineering, vol. 105, pp. 264-269, Jul. 2011.

[3] A. Farah, and C. M. Donangelo, "Phenolic compounds in coffee," Brazilian Journal of Plant Physiology, vol. 18, pp. 23-36, Mar. 2006.

[4] A. Farah, M. Monteiro, C.M. Donangelo, and S. Lafay, "Chlorogenic Acids from Green Coffee Extract are Highly Bioavailable in Humans," Journal of Nutrition, vol. 138, pp. 2309-2315, Dec. 2008.

[5] A. Farah, M.C. Monteiro, V. Calado, A.S. Franca, and L.C. Trugo, "Correlation between cup quality and chemical attributes of Brazilian coffee," Food Chemistry, vol. 98, pp. 373-380, 2006.

[6] A. Farah, T. De Paulis, C.L. Trugo, and P.R. Martin, "Effect of roasting on chlorogenic acid lactones in coffee," Journal of Agricultural and Food Chemistry, vol. 53, pp. 1505-1513, Mar. 2005.

[7] A. Podsedek, "Natural antioxidants and antioxidant capacity of Brassica vegetables: A review," Food Science Technology, vol. 40, pp. 1-11, Jan. 2007.

[8] A. Yashin, Y. Yashin, J.Y. Wang, and B. Nemzer, "Antioxidant and Antiradical Activity of Coffee," Antioxidants, vol. 2, pp. 230-245, Sep. 2013.

[9] A.A. Paguio. (2011). Light-roasted coffee contains more antioxidants -study. [Online] Available: http://www.philstar.com

[10] B. Cammerer, and L.W. Kroh, "Antioxidant activity of coffee brews," European Food Research and Technology, vol. 223, pp. 469474, Feb. 2006.

[11] C. Somporn, A. Kamtuo, P. Theerakulpisut, and S. Siriamornpun, "Effects of roasting degree on radical scavenging activity, phenolics and volatile compounds of Arabica coffee beans (Coffea Arabica L. cv. Catimor)," International Journal of Food Science and Technology, vol. 46, pp. 2287-2296, Aug. 2011.

[12] C.R. F. Souza, I.A. Schiavetto, F.C.F. Thomazini, and W.P. Oliveira, "Processing of Rosmarinus officinalis Linne Extract on Spray and Spouted Bed Dryers," Brazilian Journal of Chemical Engineering, vol. 25 , pp. 59-69, Mar. 2008.

[13] D. Fusco, G. Colloca, M.R. Lo Monaco, and M. Cesari, "Effects of antioxidant supplementation on the aging process," Clinical Interventions in Aging, vol. 2, pp. 377-387, Sep. 2007.

[14] E. Balamurugan, and V.P. Menon, "In vitro radical scavenging activities of Chrysaora quinquecirrha nematocyst venom," Drug Discoveries \& Therapeutics, vol.3, pp.56-61, Apr. 2009.

[15] E. Nebesny, and G. Budryn, "Antioxidative activity of green and roasted coffee beans as influenced by convection and microwave roasting methods and content of certain compounds," European Food Research and Technology, vol. 217, pp. 157-163, Aug. 2003.

[16] G. Sacchetti, C. Di Mattia, P. Pittia, and D. Mastrocola, "Effect of roasting degree, equivalent thermal effect and coffee type on the radical scavenging activity of coffee brews and their phenolic fraction," Journal of Food Engineering, vol. 90, pp. 74-80, Jan. 2009.

[17] I. Lopez-Galilea, A. Susana, L. Isabella, M. Paz de Pena, and C. Cid, "Influence of torrefacto roast on antioxidant and pro-oxidant activity of coffee," Food Chemistry, vol. 94, pp. 75-80, Jan. 2006.
[18] I.G. Hwang, Y.J. Shin, S. Lee, J. Lee, and S. M. Yoo, "Effects of different cooking methods on the antioxidant properties of red pepper (Capsicum annuum L.)," Preventive Nutrition and Food Science, vol. 4, pp. 286-292, Dec. 2012.

[19] J. K. Moon, H.S. Yoo, and T. Shibamoto, "Role of Roasting Conditions in the level of Chlorogenic acid content in Coffee Beans: Correlation with Coffee Acidity," Journal of Agricultural and Food Chemistry, vol. 57, pp. 5365-5369, May 2009.

[20] J.A. Vignoli, D.G. Bassoli, and M.T. Benassi, "Antioxidant activity, polyphenols, caffeine and melanoidins in soluble coffee: The influence of processing conditions and raw material," Food Chemistry, vol. 124, pp. 863-868, Jul. 2011.

[21] L. Votavova, M. Voldrich, R. Sevcik, H. Cizkova, J. Mlejnecka, M. Stolar, and T. Fleisman, "Changes of Antioxidant Capacity of Robusta Coffee during Roasting," Czech J. Food Sci., vol. 27, pp. 549-552, 2009.

[22] M. G. Bita, and M. Preda, "The Effect of Temperature and Roasting Degree on the Total Phenolic Content of Coffee Brews," Scientific Study \& Research, vol. 2, pp. 239-242, 2005.

[23] M. Nardini, E. Cirillo, F. Natella, and C. Scaccini, "Absorption of Phenolic Acids in Humans after Coffee Consumption," Journal of Agricultural and Food Chemistry, vol. 50, pp. 5735-5741, Sep. 2002.

[24] M. S. Butt, A. Ahmed, M. T. Sultan A Imran, M. Yasin, and M. Imran, "Evaluating the effect of decaffeination on nutritional and antioxidant status of different coffee brands," Internet Journal of Food Safety, vol. 13, pp. 198-207, 2011.

[25] M.D. Del Castillo, J.M. Ames, and M.H. Gordon, "Effects of roasting on the antioxidant activity of coffee brews," Journal of Agricultural and Food Chemistry, vol. 50, pp. 4625-4631, May 2002.

[26] M.D. Del Castillo, M.H. Gordon, and J.M. Ames, "Peroxyl radicalscavenging activity of coffee brews," European Food Research and Technology, vol. 221, pp. 471-477, Apr. 2005.

[27] O. Yumrutus, A. Sokmen, and N. Ozturk, "Determination of in vitro antioxidant activities and phenolic compounds of different extracts of Salvia verticillata ssp. Verticillata and spp. amasiaca from Turkey's flora," Journal of Applied Pharmaceutical Science, vol. 1, pp. 43-46, Dec. 2011.

[28] R. O. Couto, E.C. Conceicao, L.T. Chaul, E.M.S. Oliveira, F.S. Martins, M.T. F. Bara, K. R. Rezende, S.F. Alves, and J. R. Paula, "Spray-dried rosemary extracts: Physicochemical and antioxidant properties," Food Chemistry, vol. 131, pp. 99-105, Mar. 2012.

[29] R.G. Muschler, "Shade improves coffee quality in a suboptimal coffee zone of Costa Rica," Agroforestry Systems, vol. 85, pp. 131139, Jan. 2001.

[30] S.E.W. Opitz, S. Smrke, B.A. Goodman, M. Keller, S. Schenker, and C. Yeretzian, "Antioxidant Generation during Coffee Roasting: A Comparison and Interpretation from Three Complementary Assays," Foods, vol. 3, pp. 586-604, Nov. 2014.

[31] T. Katsube, Y. Tsurunaga, M. Sugiyama, T. Furuno, and Y. Yamasaki, "Effect of air-drying temperature on antioxidant capacity and stability of polyphenolic compounds in mulberry (Morus alba L) leaves," Food Chemistry, vol. 113, pp. 964-969, Apr. 2009.

[32] V. Brezova, A. Slebodova, and A. Stasko, "Coffee as a source of antioxidants: An EPR study," Food Chemistry, vol. 114, pp. 859-868, June 2009.

[33] V.L. Singleton, R. Orthofer, R.M. Lamuela-Raventos, and P. Lester, "Analysis of total phenols and other oxidation substrates and antioxidants by means of Folin-Ciocalteu reagent," Methods in Enzymology, vol. 299, pp. 152-178, 1999.

[34] W.J. Yen, B.S. Wang, L.W. Chang, and P.D. Duh, "Antioxidant Properties of Roasted Coffee Residues," Journal of Agricultural and Food Chemistry, vol. 53, pp. 2658-63, Apr. 2005.

[35] Y. Choi, S.M. Lee, J. Chun, H. B. Lee, and J. Lee, "Influence of heat treatment on the antioxidant activities and polyphenolic compounds of Shiitake (Lentinus edodes) mushroom," Food Chemistry, vol. 99, pp. 381-387, Sept. 2005.

[36] Y. Z. Liu, and D.D. Kitts, "Confirmation that the Maillard reaction is the principle contributor to the antioxidant capacity of coffee brews," Food Research International, vol. 44, pp. 2418-2424, Oct. 2011.

[37] Y.F. Chu, Ed., Coffee: Emerging Health Effects and Disease Prevention, John Wiley \& Sons, 2012, vol. 59. <Hatzold>

[38] M.I.S. Abdelhady, A.A. Motaal, and L. Beerhues, "Total phenolic content and antioxidant activity of standardized extracts from leaves and cell cultures of three Callistemon species," American Journal of Plant Sciences, vol. 2, pp. 847-850, Dec. 2011. 